\title{
Research on Second-hand Vehicle Evaluation System Based on \\ Improved Replacement Cost Method
}

\author{
Chang Jiangxue ${ }^{1, a}$, Zhang Yuquan ${ }^{1, b}$ \\ 1Jiangsu Vocational Institute of Commerce, Nanjing 211168, China \\ acjxsnow@126.com , b1767120605@qq.com
}

Keywords: Improved replacement cost method ; second-hand car value assessment ; system

\begin{abstract}
In order to meet the needs of second-hand car value assessment, the used car value assessment system has been designed based on the improved replacement cost method. The system includes system management module, used car parameter management module, used car evaluation management module and evaluation information inquiry module. We enter the relevant basic information of second-hand car information, and figure out the used car's new rate, the purchase price and the selling price through the calculation to the system.
\end{abstract}

\section{Introduction}

In recent years, China's second-hand car trading volume and transaction amount have increased year by year. The transaction amount is from 315.14 billion to 553.54 billion since 2011 to 2015 . In 2015 , the transaction volume of used vehicles have reached $9,414,700$, so the valuation of used vehicles became a hot spot of concern and research. The improved replacement cost method is widely used in second-hand car value assessment. This article designs a second-hand car value assessment system based on the improved replacement cost method.

\section{Improve replacement cost method}

\section{Determine the replacement cost}

The price index method and the direct method are usually used when calculating the replacement cost. The price index method is a method of calculating the replacement price, which is based on the original cost price of the evaluated vehicle and the current price level. The formula is as follows:

$$
Q=Z \times \frac{P_{x}}{P_{y}}
$$

Q-replacement cost;

$\mathrm{P}_{\mathrm{x}}$ - the price index when the vehicle is evaluated;

Z-the original cost;

$\mathrm{P}_{\mathrm{y}}$-the price index when the vehicle is purchased.

The price index method is applicable to eliminated products or imported cars that cannot obtain market prices. The direct method is also called the reset algorithm. This algorithm is used in the following two situations.

1) If the vehicle is assessed as a transfer of ownership, the replacement full price of the assessed vehicle is the current market price of the assessed vehicle. Other costs are ignored. 
2) If the vehicle assessment is a change in the economic behavior of the company's industry, the current market price of the vehicle, the taxes on the use of vehicles and vessels collected by the relevant authorities of the national government, education fees and vehicle purchase surcharges must be taken into account when calculating the replacement cost.

\section{Determination of the new rate}

\section{Various depreciation rates}

1) Mileage depreciation rate $n_{2}$.

$$
n_{2}=\frac{I \bullet y_{\max }-I_{\max } \bullet y}{I_{\max } \bullet y_{\max }}
$$

I-the mileage;

$I_{\max }$-the end-of-life; $y$-the number of years used;

$y_{\max }$-the number of years of scrap.

2)Depreciation rate for years $n_{1}$

$$
n_{1}=\sum_{i=1}^{t} a(1-a) t^{-1}
$$

$\mathrm{a}=2 / \mathrm{N}, \mathrm{N}-$ the service life;

$\mathrm{t}$ - a certain year for the motor vehicle during its use period.

When using the formula (2) for calculation, if there is still a balance within the service life, the straight-line depreciation method shall be used after the ninth year in order to allocate the total amount of depreciation to the end of the use period. This study uses the double-declining balance depreciation method. This method is more suitable for the depreciation of used cars.

3) Fuel consumption exceeding depreciation rate $n_{4}$

$$
n_{4}=\frac{c}{c_{\max }} \times 0.1
$$

c-the actual fuel consumption exceeding the standard rate;

$\mathrm{c}_{\max }$-the national maximum fuel consumption rate $(15 \%)$

4) Fault depreciation rate $n_{3}$

$$
n_{3}=\frac{M}{Q} \times 1
$$

M-the repair cost;

Q-the replacement cost

\section{The new rate $n$}

$$
n=1-\sum_{i=1}^{4} n_{i} \quad(\mathrm{i}=1,2,3,4)
$$

\section{Used car evaluation price}

Basic purchase price $P_{\mathbf{j}}$.

$$
P_{j}=Q \times n
$$

\section{Adjustment of purchase price}

In order to improve the authenticity of the second-car price assessment, it is necessary to readjust 
the evaluation price of the second-car according to the vehicle's own market supply and demand, market competition, routine maintenance, and the technical condition of the vehicle itself. We use the analytic hierarchy process to determine the weights of different factors, and adopt expert scoring to construct judgment matrix.

\section{Design of second-hand car valuation system based on improved replacement cost method}

When designing the system, the second-car evaluation process should be analyzed at first. And then the function module and database of the second-hand car evaluation system are designed, and finally the interface design of the system is completed.

\section{Second-hand car identification assessment system hierarchy}

In the logic design of the used car value evaluation system, the system's calculation work is dispersed in the application program. The designed system can complete the input of used car information, store the input in data form, and process the data according to the operation instructions of the improved replacement cost method. The system uses B/S structure.

Presentation layer: It mainly implements the interaction between users and systems and consists of Web pages with different functions. The user presentation layer displays the system to different users. The user makes requests to the business logic layer through operations such as selection and input. The result of the process is returned to the presentation layer and displayed to the user.

Business Logic Layer: This layer is the middle layer between the presentation layer and the data access layer and is the most critical part of the system. This section uses IIS on the Windows platform and programming language uses ASP. This layer composed of upload components and file management components. The upload component can upload the picture information of the used car; the file management component can add, delete, and other operations on the file.

Data access layer: It mainly saves and reads data, and reads the information stored in the database to the business logic layer. Data reading is done by the ADO component, and the data processed by the business layer is saved in the database. ADO components include Connection, Command, and Recordset. Connection is used to establish a connection with the database ; Command is used to execute commands on the database, such as query, add, delete, modify records, etc. The data in the database is sent to the user program through the record set, and the updated data is also returned to the database through the record set ; Recoulset used to get the recordset returned from the database.

Data Storage Layer: Mainly responsible for storing used car value assessment system information. Most of the data of the system is generated according to the constraint as the business progresses. Model data, vehicle data and user information are all stored in this database. The database used in this design is Microsoft SQL Server 2008.

\section{System Process Analysis}

When evaluating a second-hand car, selecting the appropriate valuation model is necessary. According to the need to enter the evaluation parameters, different valuation models need to enter different parameters. According to the evaluation parameters input by the system, the client verifies the validity of the entered form data through the data verification control. If the verification is valid, we should submit the entered form data to the server. The server generates an improved replacement cost method valuation formula to calculate vehicle prices based on formulas and parameters, and save the calculation result to the database, and return the calculation result to the client as well as.

\section{Design of system function module}

The second-hand car value assessment system is mainly used to evaluate the value of 
second-hand car and provide information on the valuation of used cars. The system mainly includes a system management module, a second-hand car parameter management module, a second-hand car evaluation management module, and an evaluation information query module. System management module is mainly to achieve user management and system login. After the user is registered, the user name and password of the system are obtained. If the user name and password are correct, the user enters the system and check related information. If you make a mistake, relevant tips should be made. The administrator of the system can manage the registered user information, including adding, deleting, etc., but cannot modify the related parameters of the system.

The parameter management module is mainly used to input the relevant parameters of the second-hand car, calculate the new rate of the second-hand car according to the corresponding calculation formula, and display the related calculation result. The system administrator can add and retrieve value of the second-hand car's vehicle condition parameters and new rate options.

The second-hand car evaluation management module is mainly to obtain the evaluation price of the second-hand car and to evaluate the sale price. Click Save to save the data information in the system database.

The evaluation information query module stores vehicle information that has been evaluated. Through this module, the parameters of the second-hand car, the evaluation price, and the evaluation price of the second-hand car can be queried.

\section{Conclusions}

This article has designed the used car value evaluation system, which is based on the improved replacement cost method. The results show that the system application effect is better. Due to the short system design time, the system's function is not perfect. In the next step, the actual application effect of the system will be tested and evaluated. It is expected that the system will eventually meet the automotive evaluation requirements.

\section{References}

[1] Tu Weixing. Research on Used Car Evaluation System[J]. Nanjing: Nanjing Forestry University, 2008.

[2] Liu Lijuan , Liang Tianran. Replacement Cost Method_-Discussion on the Appraisal Method of Used Car Identification [J]. Chinese business community, 2010(9): 37-38.

[3] Zhou You. Research on the Valuation Method of Used Car Based on Replacement Cost Method [D]. Jinzhou: Liaoning Agricultural University, 2014.

[4] ZHU Si-hong, ZHANG Chao.Study on PID Control Simulation of Tractor Electro-hydraulic Suspension System [J]. China Manufacturing Information, 2008,37 (21): 49-53.

[5] Wei Wei, He Yan. Intelligent control basis [M]. Beijing: Tsinghua University Press, 2008: 101-166.

[6] PANG Chang-le, ZONG Bo-hua, E Zhuo-mao. Fuzzy comprehensive control model and simulation experiment of tractor operating unit [J] .Journal of Agricultural Engineering, 2003,19 (4): 111-113. 